\title{
Implementation and usage aspects for floors in the residential houses
}

\author{
Wioletta Raczkiewicz ${ }^{1, *}$, Artur Wójcicki ${ }^{1}$ \\ ${ }^{1}$ Kielce University of Technology, Al. Tysiąclecia P.P. 7, 25-314 Kielce, Poland
}

\begin{abstract}
Concrete floors at the building's rooms are made of concrete, as well as fibre-reinforced concrete, or with the reinforcement meshes of various kinds. On one hand, such aspects have an influence on technical capabilities, as well as cost and labour-consumption when making the floors; on the other hand, they influence operational properties. The floors, as a result of significant dimensions, are particularly vulnerable to cracks, following the overlapping effects of shrinkage and thermal strains, as well as mechanical loads. Detailed design guidelines concerning the implementation method and the recommended materials (application of the respective plasticising admixtures and reinforcement, various kinds of steel meshes or a distributed reinforcement as steel or polypropylene fibres) have been developed, in order to prevent the cases above. It is visible (according to a great deal of experimental research) that the abovementioned guidelines limit the undesired shrinkage effects. Nevertheless, average typical conditions for making the floors very often differ from those in the guidelines, which may lead to the appearance of future shrinkage cracks, irrespectively to the applied reinforcement. The paper presents conclusions from the analysis of research results for three types of concrete ground floors made in the detached residential house, in the same operational conditions, differing with the reinforcement applied. The research was conducted from the moment of implementation and then, during the initial operational period.
\end{abstract}

\section{Introduction}

Concrete floors, depending on the building function, may be the finishing floor layer (industrial floors with the required bearing load, abrasiveness, chemical resistance etc. at warehousing spaces, in industrial buildings, halls or parking lots) or may perform the function of constructional subfloor under the finishing layers (coverings) - it generally concerns the residential and public utility buildings [1-4]. Concrete floors in the residential buildings can be implemented in wet or dry technology [2,5-7]. The cement or anhydrite binder is most often used, depending on the solution applied for floor layers or location in the building (on ground, on ceiling boards etc.) [5]. An important factor influencing on the selected implementation method for such floor is the subfloor, namely type and distribution of thermal insulation, damp-proof insulation, as well as i.e. the presence of floor heating

*Corresponding author: wiolar@tu.kielce.pl 
system. Guidelines detailing the principles for correct implementation of the floors include proper preparation of the subfloor, marking the upper level for concrete floors, designing and fixing the expansion joints, possibly dividing into technological sections (at rooms with large surfaces), the respective preparation of concrete mix, according to a recipe, proper mix application (with consideration to the environmental conditions, mainly temperature), as well as the respective curing when the concrete mix is setting and hardening [6-9]. At all times, the floor should be designed and implemented in a way protecting it against the penetration of water and humidity [10]. The most important guidelines which are presented shortly for proper implementation of the floors are not always completely reflected in practice $[11,12]$. It particularly refers to concrete ground floors made in small residential buildings. Concrete ground floors in the residential buildings, being basically the supplementary elements in terms of a bearing load (less important when it comes to the structural function), are not always made with due diligence. It results both from poor knowledge of contractors, and from not so adequate supervision in case of construction, in which the results of wrongly performed construction does not produce significant losses and do not pose direct threat to the users safety. Damages within the floors very rarely lead to emergency threats. Nevertheless, improper implementation of the floors leading to i.e. cracks and noticeable irregularities, occurring as defects during its use, lead to the decreased usage valour, thus to the decreased durability, as well as such floors requiring repairs $[12,13]$. The floor cracks most often are the result of concrete shrinkage, that develops both at time of setting (autogenous shrinkage), and concrete hardening (drying shrinkage) [14-17]. As long as the shrinkage resulting from the chemical processes (following the hydration reaction in cement) cannot be completely stopped or radically limited, what is a generally irreversible shrinkage effect, the drying shrinkage can be effectively limited $[14,15,18,19]$. When making the floors, you should aim for a shrinkage strain not exceeding $0.4 \div 0.5 \mathrm{~mm} / \mathrm{m}[6,7,11,20]$.

Therefore, when designing the floors, the effective and durable implementation method should be considered, but with the lowest level of complication and burdensomeness, at the same time. When considering the possibility of defects resulting from improper preparation of concrete mix (including lacking plasticising admixtures), the implementation errors and inadequate curing, as well as unexpected influence of environmental factors (including temperature and humidity), the reinforcement is worthy of consideration, that can limit the shrinkage in a significant way and does not allow to exceed exceeding the permitted cracks' width at concrete parts of the floor $[11,21,23]$. Ready-made steel meshes are most often used as a reinforcement in concrete floors (having various bar diameters and spacing) or various type of fibres (steel, polypropylene or occasionally basalt) or the meshes made from glass fibres $[21,23,24]$.

Research results are presented in the paper, providing comparison for influence of the applied various kinds of reinforcement on the size and progress of shrinkage in the concrete ground floor in the detached residential house. The floors were made in the same building, with the same implementation regime and in the same environmental conditions, at three rooms with similar area. Various reinforcement types were applied at every room.

\section{Research scope and method}

Concrete ground floors were made in the detached house and were the subject of research. The floor consists of following elements: the finish concrete layer with thickness of $7 \mathrm{~cm}$, the expanded styrofoam boards with thickness of $15 \mathrm{~cm}$, two layers of an insulating foil, the $\mathrm{C} 12 / 15$ concrete with thickness of $10 \mathrm{~cm}$, as well as the sand and gravel bed with thickness of $20 \mathrm{~cm}$ (Fig. 1). The CEM I 32,5R Portland cement (Ożarów) was applied in concrete floors, as well as sand and water. The following components were used per $1 \mathrm{~m}^{3}$ of 
concrete mix: cement $250 \mathrm{~kg}$, sand $1300 \mathrm{~kg}$, and water $100 \mathrm{l}$. Coarse fraction aggregates and plasticising admixtures were not used. The following reinforcement was used at three separate rooms:

a) the pressure-welded steel mesh with $10 \times 10 \mathrm{~cm}$ holes and $1 \times 2 \mathrm{~m}$ size, made from the $\phi 3 \mathrm{~mm}$ rods, at the $\mathrm{R}-\mathrm{S}$ room,

b) the BauCon polypropylene fibres $\sim 0.9 \mathrm{~kg} / \mathrm{m}^{3}$ (fibre length $1_{\mathrm{w}} \approx 12 \mathrm{~mm}$, diameter $\phi \approx 38 \mu \mathrm{m}$, having straight shape), at the R-PF room,

c) the reinforcement mesh made of Fola glass fibres $40 \times 40 \mathrm{~mm}$ holes, at the R-G room.

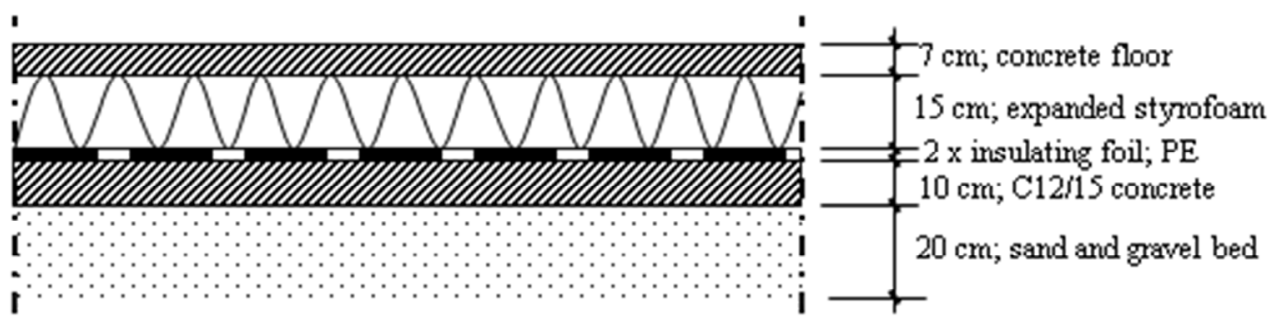

Fig. 1. Arrangement of floor layers.

Concrete floors were made in last days of October. At time of mix setting, in the subsequent two days, the environmental temperature amounted to $\mathrm{T} \approx 7 \div 10^{\circ} \mathrm{C}$, humidity $\mathrm{RH} \geq 80 \%$ (rainy days). Therefore, concrete floors did not require any significant curing. The concrete drying process was slow in such conditions. A pictures made during the implementation of concrete floors (at three various rooms, where various reinforcement types were applied) are shown in fig. 2.
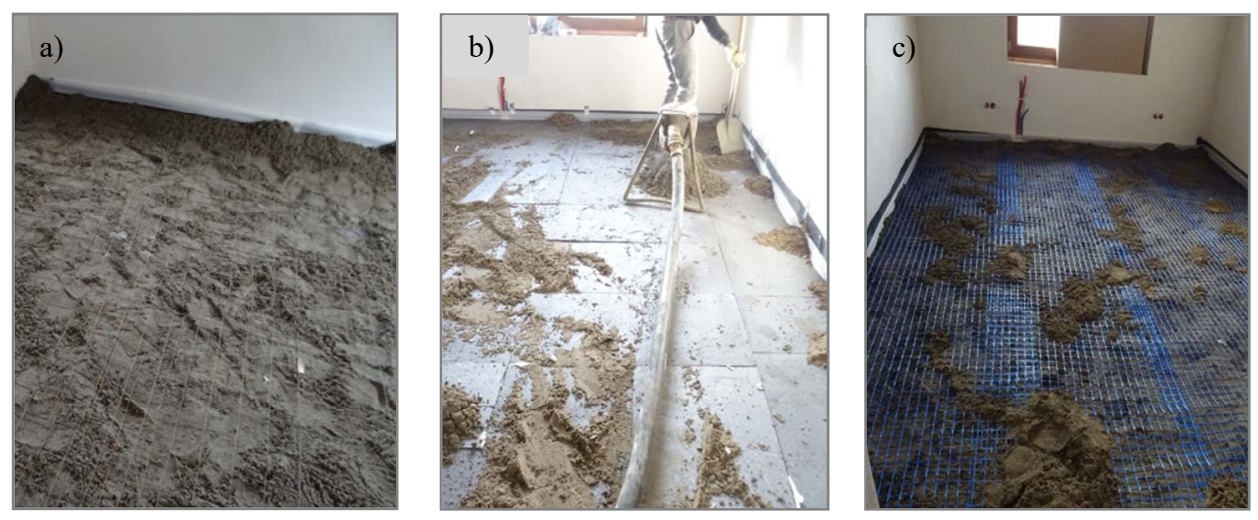

Fig. 2. Pictures from the conducted construction works: a) the R-S room, b) the R-FP room, c) the R-G room.

After making the floors, measurements of shrinkage strains at the designated fields were planned. Because of high humidity and wet surface of the concrete floor, benchmarks for strain measurements could not be glued, until third day from the moment of making the floors, thus measurements of shrinkage strains started from the fourth day. Location of measurement bases at particular rooms is shown in fig. 3 . 

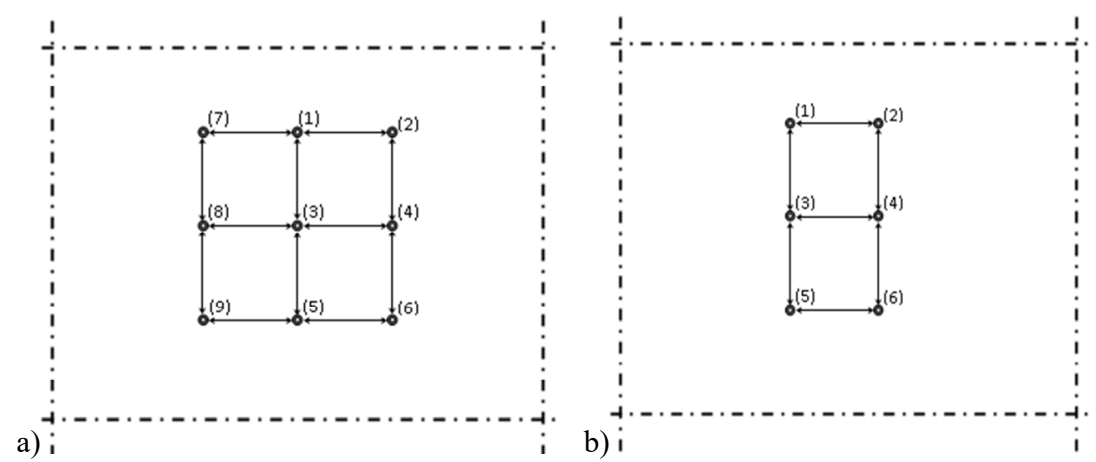

Fig. 3. Drawing for the location of measurement bases: a) the R-S room, b) the R-FP and R-G rooms.

The Demec extensometer ( $\left.\mathrm{N}^{\circ} 4938\right)$, manufactured by W.H. Mayes \& Son, with $200 \mathrm{~mm}$ base and accuracy of $0.002 \mathrm{~mm}$ (extensometer constant $0.79 \times 10^{-5}$ ) was used for the measurements. The shrinkage was measured directly at the concrete floors, in the real environmental conditions, at daily intervals at the beginning, then at intervals of several days (according to the guidelines provided in [25]).

\section{Analysis for obtained results}

The results obtained from the shrinkage strains measurements are presented in the form of graphs in Fig. $4 \mathrm{a}-\mathrm{c}$ and Fig. 5. The graphs of shrinkage registered at the individual measurement bases, as well as the average arithmetic shrinkage from such measurements evaluated in every room are shown in Fig. 4.

According to the graphs, the most compliant trends for shrinkage increase (irrespectively to the base and direction of measurements) were registered for bases in the room R-FP (where polypropylene fibres were used). Differences for shrinkage results measured at a particular day in various bases amounted to $0.05 \div 0.12 \%$; and they differed from the average value with maximally $\sim 20 \%$. In other rooms, namely the R-S and R-G rooms (where the steel mesh or the fibre glass mesh were used) scatter of results was significantly larger. In the R-S room (where the steel mesh was applied), differences between the lowest and the largest strain value amounted to $0.09 \div 0.33 \%$ and differed from the average value with maximally $\sim 50 \%$. Whereas, in the $\mathrm{R}-\mathrm{G}$ room (where the glass fibre mesh was used) it amounted to $0.16 \div 0.328 \%$, and maximum difference from the average value amounted to $\sim 45 \%$. At this stage, observation for visible variation in the influence of the applied concrete floor reinforcement on its behaviour, at time of binding and in the period of initial use, was enabled.

The graphs for average shrinkage strains evaluated from the measurements in the three rooms and for simultaneously registered environmental parameters (ambient humidity and temperature) are presented in Fig. 5. Data presented above enabled evaluation of differences in the shrinkage size, depending on the reinforcement applied, as well as analysis for the influence of environmental conditions on the strain increase. 
a)
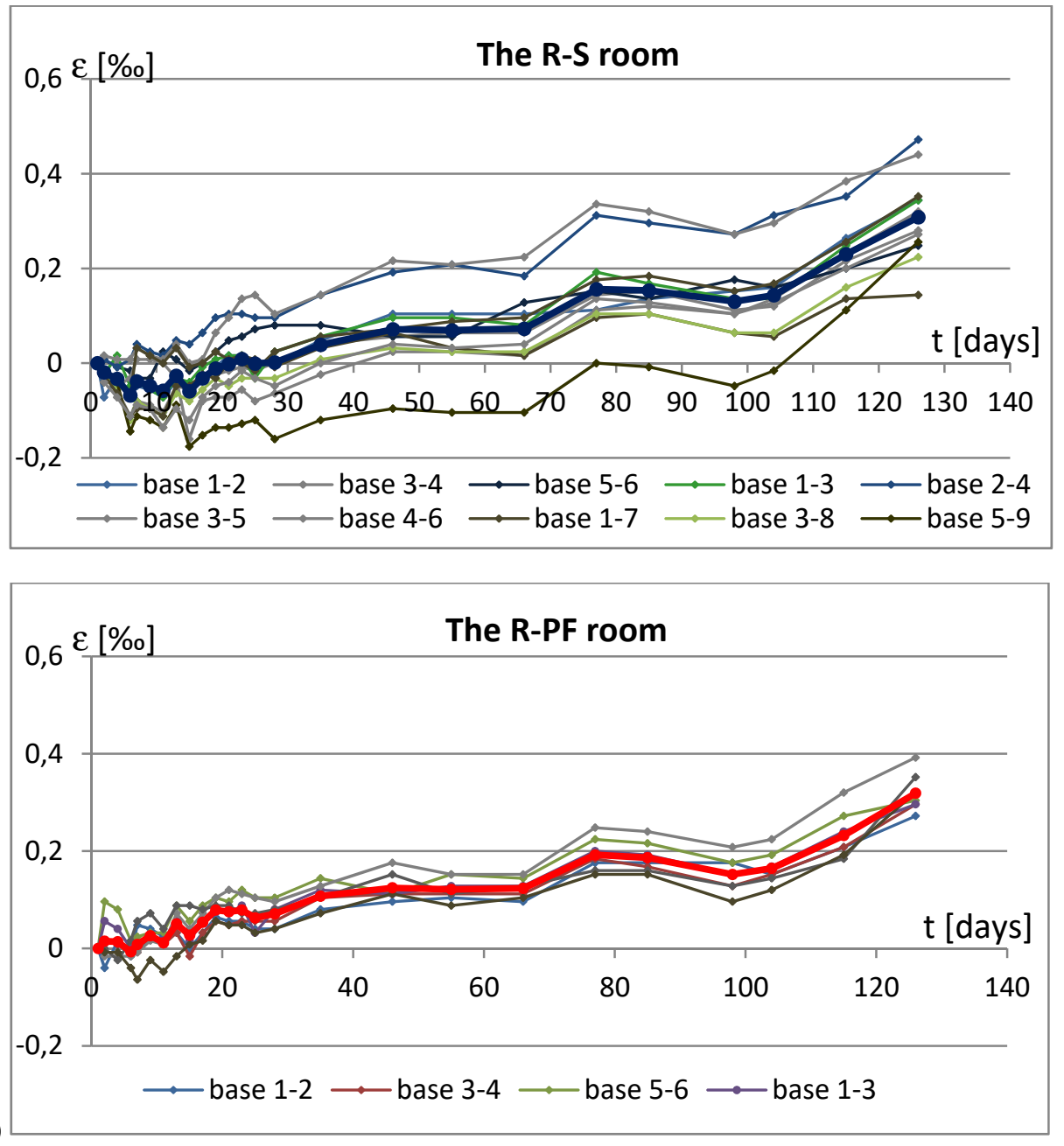

c)

$\varepsilon[\%]$

The R-G room

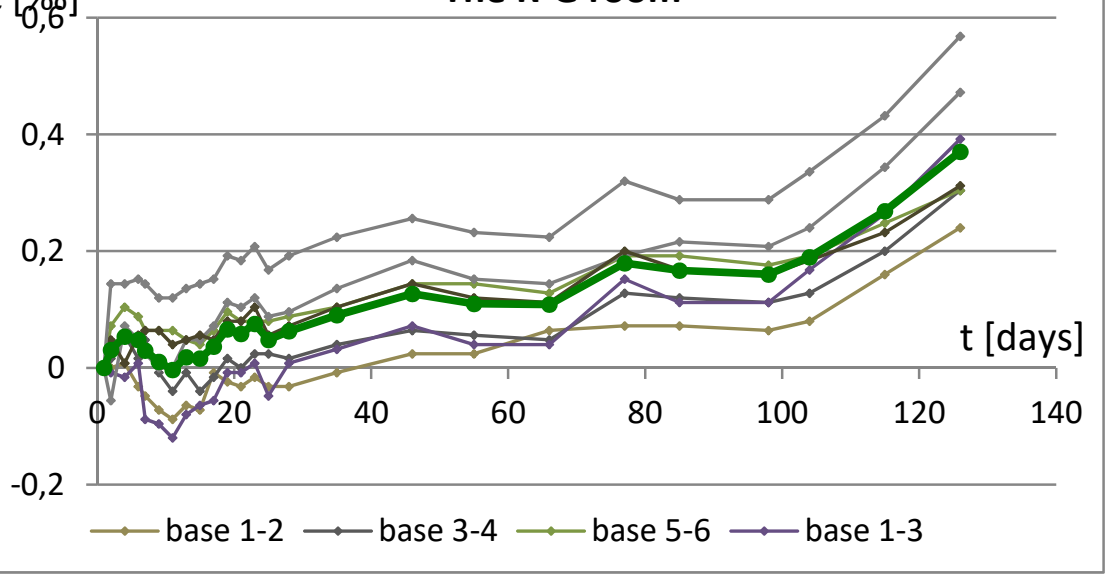

Fig. 4. Graphs for changes of shrinkage strains for three concrete floors: a) the R-S room, b) the R-FP room, c) the R-G room. 


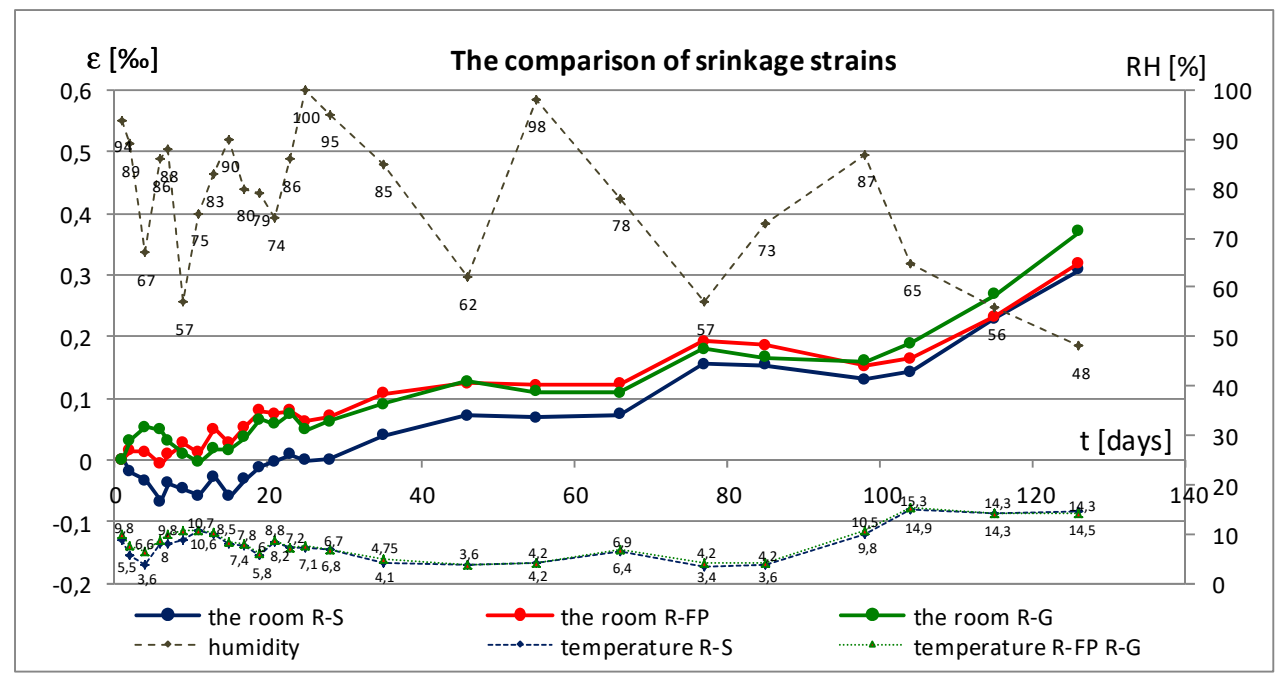

Fig. 5. Graphs for average shrinkage strains increases in the concrete floors in three rooms, as well as graphs for humidity and temperature changes.

The obtained results demonstrate very similar trends in shrinkage strains changes, as a function of temperature and humidity, for the observed areas, in all three rooms. Nevertheless, the shrinkage strain values are visibly diversified. The lowest shrinkage growth at first two months from concrete setting was registered in the R-S room (where the steel mesh was applied). It can probably result from the fact, that at first days from making the concrete floor, temperature in such room was $1 \div 2^{\circ} \mathrm{C}$ lower than in other rooms, which influenced the slowed down mix setting and concrete drying. When the humidity exceeded $80 \%$, the swelling of concrete was even observed. Initial differences in shrinkage strain values in the R-S room, in relation to strains measured in the R-FP and R-G rooms, lasted at the subsequent days. Only in the third month of the measurements, the shrinkage in the R-S room started to increase more rapidly than in other rooms. At the last day of the measurements, the shrinkage growth measurements in the R-S and R-FP rooms were almost identical: $\varepsilon_{\mathrm{R}-\mathrm{S}}=0.310 \%, \varepsilon_{\mathrm{R}-\mathrm{FP}}=0.318 \%$. The largest shrinkage was registered in the $\mathrm{R}-\mathrm{G}$ room (concrete floor with glass fibre mesh), $\varepsilon_{\mathrm{R}-\mathrm{G}}=0.370 \%$. It was $\sim 17 \%$ larger than in other two rooms.

The changes in the environmental humidity significantly influenced the recorded shrinkage strain values. In the first 21 days since making the concrete floor, the humidity did not fall below 50\% (the measurements indicated $\mathrm{RH}>80 \%$ many times), which significantly limited the shrinkage, even leading to the reverse shrinkage strain changes. Finally, the longer period with a decreased humidity, after the moment the concrete was bound (between 25 and 46 days of measurements), had an influence on the accelerated concrete drying and gradual shrinkage growth. Whereas, a visible increase in shrinkage strains began from the $98^{\text {th }}$ day of measurements, namely from the moment of switching on the heating and the temperature increase with $\sim 10^{\circ} \mathrm{C}$, which visibly accelerated the drying process.

From the moment these papers are completed, the research has not stopped, and the measurements of shrinkage, humidity and temperature are continuing until making the floor covering. 


\section{Conclusions}

1. The concrete shrinkage growth visible depends on the environmental conditions: the humidity and temperature.

2. The environmental humidity exceeding $\mathrm{RH}=80 \%$, in the initial period of concrete hardening, inhibit the shrinkage, and even leads to the concrete swelling.

3. The decreased environmental temperature, $\mathrm{T}=3 \div 4{ }^{\circ} \mathrm{C}$, in the initial period of concrete hardening slow down drying process and decrease the initial shrinkage.

4. Among three reinforcement types applied in the concrete floors, the least effective is the glass fibre mesh, in terms of limiting the shrinkage.

5. The final shrinkage values measured in floors with the polypropylene fibres or the steel mesh are all almost identical.

6. Application of the reinforcement in the form of polypropylene fibres increases homogeneity and produces isotropy in the concrete floor layer, as well as shrinkage strain sizes that are similar, irrespectively to the direction of measurements.

7. It is demonstrated in the scope of the obtained results, that the reinforcement in the form of polypropylene fibres is the most effective reinforcement type from all types applied in the concrete floors, following its easy application and simultaneously efficient limitation of shrinkage.

\section{References}

1. B. Chmielewska, L. Czarnecki, Proceedings, XXVI OKWPPK, 1, 239-279 (2011)

2. F.R. Neal, ICE. Thomas Telford, 62 (2002)

3. A. Garbacz, Building Materials, 5, 2-5 (2007)

4. L. Czarnecki, Building Materials, 5, 6-8 (2007)

5. Z. Giergiczny, Industrial concrete floors, building, use, repair, PWN (2009)

6. ACI 302.1 R-04: Guide for Concrete Floor and Slab Construction, ACI Committee 302, 65 (2004)

7. ACI 360 R-92: Design of Slabs on Grade, ACI Committee 360 (1997)

8. A. Banyś, Proceedings, XXIII OKWPPK, 4, 83-90 (2008)

9. Technical Report 34, Third edition: Concrete industrial ground floors - a quide to their design and construction, The Concrete Society, 105, ( 2003)

10. J. Jasiczak, P. Szymański, P. Nowotarski, 15th German-Lithuanian-Polish Colloquium Meeting of EURO-Working-Group on Oper. Res. in Sust. Dev. and CE (2015)

11. J. Jasiczak, P. Szymański, Building Materials, 9, 16-19 (2006)

12. S.A. Austin, P.J. Robins, J.W. Bishop, EPSRC Grant Final Report, Loughborough University (2000)

13. T. Kulas, Proceedings, XXIII OKWPPK, 2, 295-326 (2008)

14. K. Flaga Shrinkrage stress and subsurface reinforcement in concrete structures, PK Publisher, Cracow (2011)

15. K. Flaga, PASTS, 63, 15-22, (2015)

16. W. Piasta, Constr. Build. Mater. 140, 395-402 (2017)

17. W. Raczkiewicz, M. Bacharz, K. Bacharz, AMS, 15, 22-29 (2015)

18. J. Silfwerbrand, J. Paulsson-Tralla, Concrete International, 22, 69-72 (2000) 
19. P.G. Kossakowski, W. Raczkiewicz, AMS, 14, 5-13 (2014)

20. Concrete industrial ground floors. A guide to design and construction, Concrete Society Technical Report, 34 (2003)

21. M. Petri, W. Spisak, Building Materials, 9, 20-25 (1998)

22. M.A. Glinicki, Cem. Lime Concrete, 13, 184 (2008)

23. H. Alsharie, Open Journal of Civil Engineering, 05,185-189 (2015)

24. P. Löber, K. Holschemacher, World Journal of Eng. and Tech., 2, 48-54 (2014)

25. ITB Instruction No 194/98: Study of mechanical properties of concrete on samples taken in the forms, ITB (1998) 